a fortnight it had regained its normal characters, no albumin belng present and no bacteria. The patient was up in a fortnight and out of doors within six weeks after the operation. He still continues well in every way, passing a catheter nightly to get rid of residual urine. The calculus measured $1 \frac{1}{2}$ in. by $1 \frac{1}{4}$ in. ; it was composed of oxalate of lime and weighed $1 \mathrm{oz}$.

Brighton.

\section{As a thitror}

\section{HOSPITAL PRACTICE, BRITISH AND FOREIGN.}

Nulla autem est alia pro certo noscendi via, nisi quamplurimas et morborum et dissectionum historias, tum aliorum tum proprias collectas habere, et inter

\section{ST. THOMAS'S HOSPITAL.}

A CASA OF PERHORATED GASTRIC ULCER; OPHRATION; RECOVERY.

(Under the care of Dr. SHARKEY.)

IT is somewhat difficult to estimate the mortality in cases of perforated gastric ulcer which have not been treated by laparotomy, but it has been stated to be 95 per cent., and we may take this number as rather an under-estimate than an over-estimate of the death-rate from this lesion, and indeed the chance of a localisation of the effused contents of the stomach can be but small. Cases of perforation of a gastric ulcer in which previously complete adhesions have formed with a neighbouring organ, such as the liver, belong to an entirely different category and should be excluded from the statistics founded on cases perforating into the peritoneum. The mortality after the operation was considered to be about 70 per cent. by Greig Smith, ${ }^{1}$ but this opinion was founded on only about 100 cases; since that time the operation has been performed much more freely and at an earlier period after the perforation, and the death-rate has certainly improved. Laparotomy for perforation of an ulcer of the stomach was first suggested by Dobson ${ }^{2}$ of Bristol, and the first operation was performed by Czerny in 1885, but the patient died. This unsuccessful result was followed by four others also ending fatally, but in $1892 \mathrm{Kriege}^{3}$ published a case in which recovery followed the operation. The cases which bave been recorded recently are numerous and we have published several in "The Mirror of Hospital Practice. ${ }^{4}$ Every case is of interest, and the two recorded below illustrate many points of importance. In the case at St. Thomas's Hospital the value of the saline intravenous injection containing brandy is especially noteworthy. Recent papers of value on the subject are those by Pearce Gould, ${ }^{5}$ by Barling, ${ }^{6}$ and by Weir and Foote. ${ }^{7}$ For the notes of the following case we are indebted to Dr. C. R. Box and Mr. Cuthbert S. Wallace.

A woman, aged thirty-three years, was admitted into St. Thomas's Hospital on Dec. 6th, 1897. The family history was unimportant. When she was fifteen years of age she first began to suffer from abdominal pain with occasional romiting. The romit had once the appearance of coffee ; the pains at first appeared to have no definite relation to the ingestion of food or to exercise. The patient was in service and was believed to have strained herself in making a bed. From this time onward she was unable to eat meat, since it induced pain and vomiting. She had lived on milk, gruel, and fish, but the latter at times also disagreed. Five years before admission she was treated for anæmia and three years later she had hæmatemesi which succeeded an attack of vomiting. Soon after thi another profuse hæmorrhage from the stomach took place.

Abdominal Surgery, vol i., p. 570 gical Journal 1883 3 Berliner Klinisue Wochenschrift, 1892,1280

4 THE LaNChT, March 20th, 1897, p. 806; Jan. 15th, 1898, p. 158 ; and April 2nd, 1898, p. 930 .

$$
\begin{aligned}
& \text { Med. Jour., 1894, vol. ii., p. } 859 . \\
& \text { Ibid., 1895, vol. i., p. } 1314 \text {. }
\end{aligned}
$$

7 Medical News, Philadelphia, 1896, Aug. 25th
For fifteen months prior to admission to hospital she had been treated as an out-patient for gastric ulcer. The pain latterly had become more severe. Whilst walking back from her work at about 5.45 P.M. on Dec. 6th she was suddenly seized with a sharp pain in the left side just below the ribs. She reeled and would have fallen had not her sister, who was walking with her, caught her. She was carried into a shop, where she waited until a cab was procared and she was then taken to the hospital. On the way she romited some brownish matter which was described as having the appearance of cocoa. During the day she had takenat 7.45 A.M., bread and butter for breakfast; at midday, bovril ; and at 4.15 P.M., cocoa and a biscuit. When seen at 7 P.M. the patient had an anxious expression and was complaining of intense pain in the epigastric and left hypochondriac regions. She lay on her back, with the abdomen rigid but not distended. Percussion showed a normal area of liver dulness and no indication of any fluid in the flanks. The epigastric and left hypochondriac regions were acutely tender to the touch. The extremities were cold and the temperature in the axilla was $95.6^{\circ} \mathrm{F}$. The pulse was 88 , small and compressible. There was no further vomiting. The urine was acid and of specific gravity 1026; it reduced Fehling's solation rapidly. At $10 \mathrm{P} \mathrm{M}$. the abdomen was opened in the mid-line above the umbilicus. As shock was evidently great the median basilic vein was opened and three pints of normal saline fluid containing one and $a$ half ounces of brandy were infused. The appearance of the patient and the character of the pulse at once improved so that both were much better at the close of the operation than at the commencement. Immediately the peritoneum was opened several ounces of milky fluid escaped. The ulcer was found on the anterior surface of the stomach quite close to the lesser curvature and to the pylorus. Though somewhat deep in the abdomen it could be dragged down under the wound. The perforation was about balf an inch in diameter and was surrounded on all sides by a ring of thickening. The induration was of such extent that excision was out of the question. The ulcer was therefore inverted with a double row of Lembert's sutures and was closed by an omental graft. The intestines were then turned out on to the surface of the abdomen and were washed with sterile water; the abdominal cavity and the pelvis were carefully cleaned with sponges. The pelvis contained stomach contents, but there was no sign of peritonitis. A drain having been introduced through an incision below the umbilicus the operation wound was closed. For fifteen days after the operation the patient was fed by the rectum; but then food in gradually increasing quantities was given by the mouth. The condition of the abdomen never gave cause for anxiety. For a few days after the resumption of solid food abdominal pain was present, but thenceforward the recovery was uneventful. The reducing agent was never present in the urine after the operation. The patient was discharged from the hospital on Feb. 24th, 1898, and is now in the best of health.

\section{SOUTHPORT INFIRMARY.}

A CASE OF PEREORATED GASTRIC ULCER; OPHRATION; RECOVERY.

\section{(Under the care of Mr. G. RhinhaRDT ANDERSON.)}

A YOUNG woman, who was apparently in good health, consulted Mr. Reinhardt Anderson on Feb. 18th, 1897, complaining of pain after food. The pain was not constant and was not accompanied by vomiting. She had romited after every meal on the 16th, but this she attributed to a bilious attack. She had never vomited blood. The pain had, she stated, existed off and on for some months. Mr. Anderson subsequently ascertained that twelve months previously-viz., in the early part of 1896-she was a ward maid in the infirmary, but she had to give ap her situaticn because of anæmia and persistent dyspepsia. On examination the patient was found to be somewhat anæmic with pain and local tenderness in the epigastrium. Mr. Anderson prescribed a milk diet and the usual remedies. On the 21st, at 5 P.M., he received a call to see her as it was thought that she was dying. On his arrival he found that she was in a state of profound collapse; there was profuse perspiration, the face was ashen, and she had a rapid thready pulse. She complained of severe abdominal pain. There had been no 
vomiting. It seemed that after ealing a very hearty meal at 1 P.M., consisting of calf's heart, peas, potatoes, and pastry, she had taken a walk of over three miles. When nearing home at $4.45 \mathrm{P}$ M. she was suddenly seized with such severe pain in the abdomen that it was necessary to put her in a cab to get her home, though it was only three or four hundred yards away. From this history Mr. Anderson suspected perforation of a gastric ulcer and on examining the abdomen he made out the following facts. The abdominal walls were rigid, hardly moving at all with respiration ; there was marked tympanitic resonance with absence of the liver dulness to the upper border of the seventh rib, and there was shifting dulness in either flank to a small extent. Palpation elicited general acute tenderness. A small injection of morphia was given and arrangements were made for her immediate removal to the infirmary, which was over a mile distant. At 7.30 P.M (two and three-quarter hours after the onset of the pain) Mr. Anderson operated. The abdomen was opened by a mesial incision $5 \frac{1}{2}$ in. in length extending from just below the xiphoid cartilage to within an inch of the umbilicus. On entering the peritoneal cavity there was an escape of gas and turbid serum with a marked gastric odour. Flakes of lymph were already visible on the surface of the liver and the omentum as they presented in the wound. On drawing down the stomach there readily came into view a small punched-out perforation from which escaped plentifully the dark-brown fluid contents of the stomach, these at first rushing unavoidably into the peritoneal cavity. Traction on the stomach induced retching and increased the flow. The perforation was now surrounded by sponges and the contents of the stomach emptied as much as was possible into a porringer. The perforation was then secured by three rows of Lembert sutures, infolding the stomach on itself, in its long axis. Fine silk was used. The peritoneal cavity was flushed out by large quantities of sterilised water poured into the abdomen from a jug, and also by means of a glass tube; the peritoneum above and below the liver, in either flank, and in the pelvis, was thoroughly irrigated. This proceeding was continued till the flaid escaped quite clear and free from all gastric odour. Very few solid particles came into view. After systematic sponging the abdominal wound was secured in the usual way. No drain was used. The operation lasted one hour and twenty minutes and the patient bore it well. The subsequent progress was an almost uninterrupted one towards recovery. Vomiting was troublesome for the first forty-eight hours, but was relieved by sips of very hot water and powders of carbonate of bismuth. A slight attack of pleurisy with effusion on the left side appeared on the fourth day, but this gradually and completely cleared up without aspiration. Rectal feeding was maintained till the ninth day after the operation in view of the tendency of the patient to vomit and also because her general condition kept so good as not urgently to demand food by the mouth. Fish was given on the seventeenth day and chicken on the twenty-seventh day. The stitches were all removed on the ninth day, the wound soundly healed, and there was neither abdominal pain nor tenderness. The temperature, which had never been higher than $102^{\circ} \mathrm{F}$. on the second day after the operation, became normal on the thirteenth day and remained so. The patient was allowed up for the first time on March 24th and was discharged on April 29th. Eight months after the operation she travelled from Holyhead to Dublin. She was very sick, but sustained mo harm, and in April, 1898, she was in perfect health and free from all dyspeptic symptoms.

Remarks by Mr. REINHARDT ANDERSON.-In submitting the notes of this case I am aware that there is nothing very unusual to comment upon. I was fortunately able to see the patient within fifteen minutes of the perforation and I believe that the happy result was largely due to the very short time which elapsed between the occurrence of the accident and the opening of the peritoneum. I may also mention that the perforation was small, not larger than a crow quill, and was situated on the anterior surface near the cardiac end, and thongh the stomach was loaded with partially digested food not much had had time to escape into the body cavity. Moreover, I was not hampered by those difficulties which have beset many other operators when dealing with similar cases-viz., the presence of induration around the seat of the ulcer or of extensive adhesions.

The chief interest in the above case seems to me to lie in the absence of previous symptoms pointing to a gastric alcer. The patient's complaint was of vague pain and discomfort after food, her appearance was that of good bealth, and she was able to fulfil without trouble the arduous daties of waitress in a busy restaurant, so that $I$ mast confess that at $\mathrm{my}$ first and only interview with the patient 3 days before the occurrence of the acute mischief I was not impressed with the idea that she had a gastric ulcer. I prescribed the milk diet more as a precautionary measure, advice which was evidently totally disregarded. The presence of small, solitary, punched-out ulcers, which in recorded cases are found so frequently in sudden perforation of the stomach, is a matter of some interest, for they may exist without giving rise to more than ill-defined symptoms of dyspepsia, and they may easily be overlooked without careful palpation for a tender or painful area. It is certain that since my experience in the above case I have treated with more respect similar cases coming under my care, and I have enforced the absolute rest which is needful to avoid a possible perforation. In the treatment of this accident there is little doubt that the best chance for the patient lies in early diagnosis and prompt operation.

\section{ithovical Sorreties.}

\section{ROYAL MEDICAL AND CHIRURGICAL SOCIETY:}

\section{Intra.pleural Tension.}

A MEETING of this society was held on Mas 10th, the President, Mr. Bryant, being in the chair.

Dr. SAMUEL WEST read a paper on Intra-pleural Tension, of which the following is an abstract. Dr. West pointed out that the two layers of the pleura, which in bealth are in close contact, are subject to a constant strain which tends to pull them apart called the "intra-pleural tension," which is for all practical purposes equal in amount to the elastic contraction of the lung, but opposite in direction. The respiratory movements cause constant variations in this tension owing to the different degree to which the lungs are on the stretch in the different phases of respiration. Besides this, the air is somewhat hampered both on its entrance and on its exit from the air-tubes to the extent of half a millimetre of mercury on inspiration and from one and a half to two millimetres on expiration, causing a respiratory oscillation equal to about 2 in. of water. During normal quiet breathing, both on inspiration and expiration, the intra-pleural tension is negative. During forced inspiration the negative value is increased, but during forced expiration the negative value may be converted into a positive one; but as long as the two layers of the pleura are in contact this positive pressure during expiration is supported by the chest walls and does not, except theoretically, affect the pleura. Under pathological conditions, if the pleura contain air or fluid, this pressure then will affect the contents of the pleura also. The effects produced will vary according as the pleura is occupied by flaid, which is practically incompressible, or by air, which is easily compressible. The methods of estimating intra-pleural pressure are mainly two: first, measuring the elasticity of the lnng, as Donders did; and, secondly, direct investigations by passing a trocar into the pleara through the chest walls. Perl's observations were referred to and various conclusions which may be drawn from them were stated with comments. When one side of the chest is opened the admission of air goes a long way to satisfy the elasticity of the lungs on both sides. Where the two layers of the pleura are more or less adherent the intra-pleural tension is more or less diminished. Where the pleural cavity is obliterated and the one lung contracted while the other has become enlarged the elasticity of the sound lung is greatly increased, proving that this is a condition of complementary bypertrophy, and not, as it is often called, complementary emphysema. Arguments were adduced to show that the contractility of the lung was probably not purely elastic, but partly muscular, and that there was such a thing as "pulmonary tone," in the same sense as physicians speak of "vascular tone," which may vary considerably in different constitutional conditions or in different nutritive states of the lung. Under pathological conditions the two layers of the pleura may be separated either by air or by fluid, and these present each of them its own peculiarities; thus 